\title{
Global Volatility Spillover in Asian Financial Markets
}

\author{
Muhammad Ishfaq ${ }^{1^{*}}$ \\ Zhang Bi Qiong ${ }^{1}$ \\ Awais ur Rehman ${ }^{2}$ \\ ${ }^{1}$ School of Finance, Central University of \\ Finance and Economics, Beijing, China \\ ${ }^{2}$ Faculty of Economics and Business, \\ Universiti Malaysia Sarawak, Malaysia \\ ${ }^{*}$ Corresponding Author
}

Doi: 10.2478/mjss-2018-0031

\begin{abstract}
The present paper accommodates the spillover impact of market volatility index of S \& $P 500$ (VIX) and China exchange-traded fund's volatility (VXFXI) on the emerging equity (KSE-100 index) and foreign exchange markets of Pakistan. In this context, we use a vector autoregressive (VAR) model and impulse response functions (IRF) to explore link among VIX indices and financial markets of Pakistan for the differential time periods. The study concludes that a rise in both VIX and VXFXI results in price falls of KSE-100 index and deteriorates exchange rate market. This implies that VIX act as 'fear gauge' on both stock and exchange rate markets in Pakistan. These outcomes provide an imperative implication on the pattern of currency and stock sensitivities against global volatility. This reveals that adverse movements in global volatility in the USA and Chinese financial market have a significant impact and a rise in VIX causes an outflow of investment from financial markets of Pakistan. Moreover, our results may guide local and global investors to anticipate the potential direction of stock and exchange rate markets based on market volatility index.
\end{abstract}

Keyword: Market Volatility Index, VAR model, Impulse response function, financial markets, Pakistan

\section{Introduction}

Volatility spikes during Asian currency crises of 1998 in emerging markets proceeding toward the rising momentum of volatility in mature financial markets during global credit crunch 2007 have gained much importance in portfolio evaluation. Moving forward, asset and financial markets continue to price volatility across a range of asset and financial products. Volatility transmits from mature markets to emerging foreign exchange markets through movements in investment portfolios inducing capital flows across countries. Therefore, higher levels of volatility have positive implications for equity and foreign exchange markets in emerging economies. The association between volatility, equity and exchange rates, in turn, have important implications for monetary institutions in these countries. Sketching this background of volatility, however, this paper aims to analyze the association of market volatility index (VIX) patterns with equity and foreign exchange markets in Pakistan.

This paper is mainly concerned with market volatility index (VIX) that is a popular markettiming indicator of Chicago Board Options Exchange (CBOE) which gauge short-term future 
volatility, commonly known as 'investor fear gauge' (Whaley, 2000) (Whaley, 2009). In most cases, high values of VIX reflect increased investor fear and low values of VIX directs complacency. This behavioral pattern between VIX and the stock market has repeated itself in bull and bear cycles. Historically, the high levels of VIX have coincided with high degrees of turmoil in the US like 9/11 attacks, geopolitical tensions 2002 and WorldCom accounting scandal and bankruptcy (Cairns, Ho, \& McCauley, 2007). The information regarding VIX value is figured and disseminated to investors on a real-time basis. This real-time information of VIX suggests investors minute basis future estimates of underlying market up to one month to carry healthy decisions in portfolio evaluations.

Global financial integration has increased the influence of large economies over rest of the financial markets. Market developments in the U. S. have long been dominant in the global markets. The financial crises 2008-2009 and 'taper tantrum' mid-2013 are recent examples of spillover effects from U. S. markets. Meanwhile, there has been a large number of examples where market movements in China influenced other financial markets of the Asian region and beyond. A simultaneous increase in Chinese equities by $7.3 \%$ and Asian equity markets by $3.4 \%$ after the announcement of RMB 4.0 trillion stimulus package. Apart from macro policy announcements, comparatively small events in China can move Asian financial markets. The recent default of Chinese trust product in January 2014 pulled down emerging financial markets for numerous days until the resolution (Shu, He, Wang, \& Dong, 2016). Besides the US, China's increasing regional influence, trade and strategic investment linkages with Pakistan, it is pertinent to evaluate volatility impact over its financial markets. However, this study accommodates the spillover impact of market volatility index of S \& P 500 (VIX) and China exchange-traded fund's volatility (VXFXI) on the emerging equity and foreign exchange markets of Pakistan.

Most empirical literature has focused on dynamics between VIX and equity markets. The studies (Yang Cheng Lu, 2012), (Sarwar, 2012), (Kang, Ki-Hong, \& Yoon, 2014), and (Kang, YunJung, Ki-Hong, \& Sungkyun, 2014) explored the dynamic relation between VIX and equity markets. They conclude VIX plays a significant role as fear gauge indicator for investors to forecast future movements of equity markets. However, few studies established a link between VIX and exchange rates of various currencies (Kang, Ki-Hong, \& Yoon, 2014) and (Kang, Yun-Jung, Ki-Hong, \& Sungkyun, 2014) analyzed the relation of VIX with Japanese and Korean financial markets as well as the potential direction. They suggest VIX returns are negatively linked with the JPY but have a positive impact on the KRW. This implies that a higher level of VIX index causes appreciation in JPY but depreciates KRW. Likewise, the study (Cairns, Ho, \& McCauley, 2007) concludes that 'safe heaven' currencies appreciate with an increase in global volatility, unlike high-yielding currencies adopt 'flight to safety' effect and incline to depreciate.

Although studies have explored the relationship between global volatility, equity and foreign exchange markets, the role of $\mathrm{VIX}$ as an investor fear gauge has assigned little or no attention in empirical studies conducted in the Asian region. Particularly, investors are ignorant about the sensitiveness of VIX towards the emerging financial markets of Pakistan as this market ranked Asia's best-performing equity market in $\mathbf{2 0 1 6}$ and reclassified as 'emerging market index' from May 2017. We examine the equity and forex return-volatility association for Pakistani financial markets to determine whether a return-volatility relationship is significant for these markets, as well as the strength and potential direction of this relation. In this context, we use a vector autoregressive (VAR) model to investigate the relationship of implied volatility index of S \& P 500 (VIX) and volatility index of Chinese exchange-traded funds (VXFXI) with equity and foreign exchange markets of Pakistan.

The remainder of this paper is organized as follows. Section 2 discusses the data sources, descriptive statistics and methodology. Section 3 describes the empirical results and final Section 4 provides the conclusion and implications.

\section{Data and Methodology}

\subsection{Data Sources}

This paper considers daily frequency data sets of implied volatility index of S \& P 500 (VIX) in the USA 
financial market, China Exchange Traded Fund's Volatility Index (VXFXI) in the Chinese financial market, KSE-100 index and foreign exchange rate in the Pakistani financial markets from January, 2004 to October, 2016 except VXFXI that starts from March, 2011. The data sample of VIX and VXFXI are obtained from CBOE website while the data of KSE-100 index and PKR exchange is taken from highly reliable source 'Bloomberg.' Figure 1 shows the dynamics of VIX that exhibits low volatility in 2004-07 and high volatility in 2008-09. Empirically it is found that asset or stock prices are nonstationary, but their log differences are stationary as shown in figure 2 . Therefore, raw series are transformed into return series for all four variables (Kang, Ki-Hong, \& Yoon, 2014).

$$
X_{t}=\left(\log P_{t}-\log P_{t-1}\right)^{\star} 100
$$

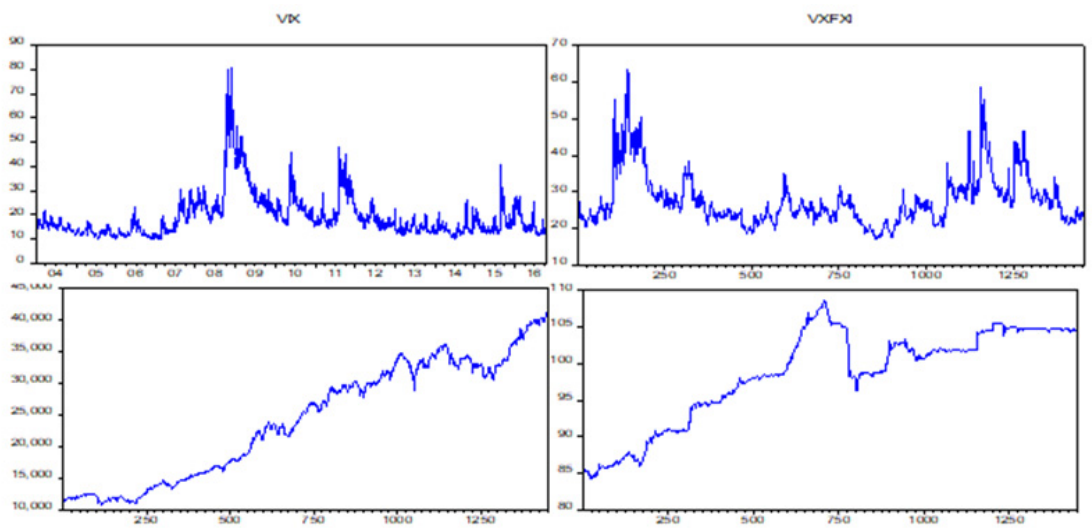

Figure 1: Series at level
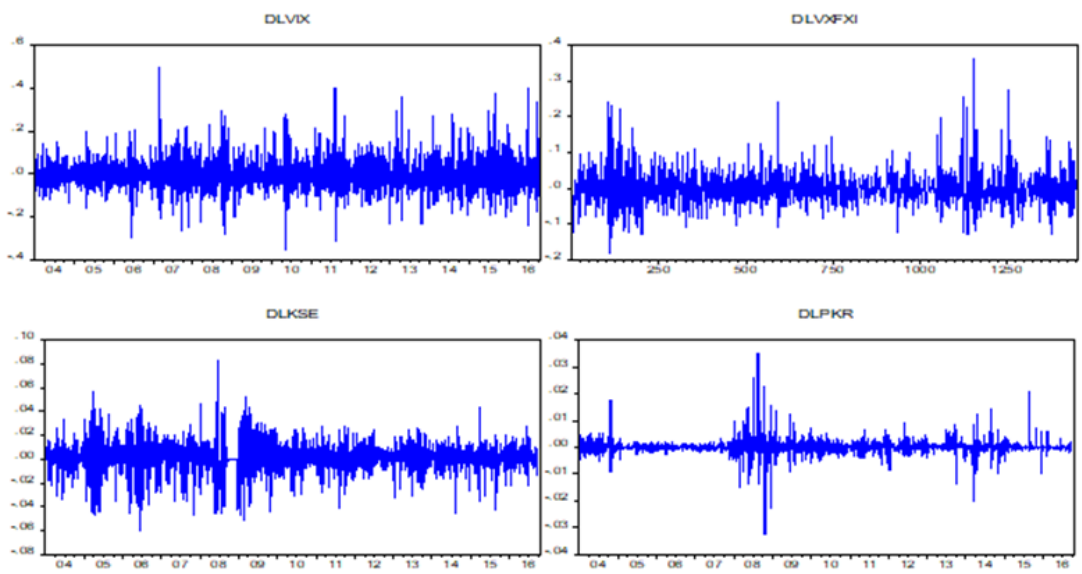

Figure 2: Return-Series

\subsection{Descriptive Statistics}

Table 1 summarizes the descriptive statistics and unit root tests for all variables. Panel A shows positive mean returns in KSE-100 index and PKR exchange rate. The highest standard deviation is found in VIX return-series, which indicate a greater change in prices. However, return series of PKR and KSE-100 index are less volatile. The skewness is positive for all except KSE-100 index which suggests that extreme negative returns for the stocks. The higher values of kurtosis points toward the occurrence of outliers and non-normal distribution in all return-series. Accordingly, the JarqueBera test precludes the null hypothesis of normal distribution at the $1 \%$ significance level for all return-series. 
Panel $B$ confirms the absence of unit root in all series at level employing the Augmented Dickey-Fuller (ADF) and Phillips-Perron (PP) tests. Both tests ADF and PP consider the same null hypothesis that a time series holds a unit root. As shown in Panel $B$, large significant values for the ADF and PP test statistics rejected the null hypothesis of a unit root at the $1 \%$ significance level, signifying that all sample returns are stationary.

Table 1: Descriptive Statistics and Unit Root Tests

\begin{tabular}{|c|c|c|c|c|}
\hline & DLKSE & DLPKR & DLVIX & DLVXFXI \\
\hline \multicolumn{5}{|c|}{ Panel A: Descriptive statistics } \\
\hline Mean & 0.0670 & 0.01804 & -0.0051 & -0.0253 \\
\hline Std. Dev. & 1.2234 & 0.2493 & 6.8663 & 4.9572 \\
\hline Skewness & -0.4270 & 0.9549 & 0.7075 & 1.1636 \\
\hline Kurtosis & 6.6476 & 42.813 & 7.2436 & 8.3855 \\
\hline Jarque-Bera & 1942.01 & 219848.5 & 2766.37 & 2079.4965 \\
\hline $\begin{array}{l}\text { Probability } \\
\text { Panel B: Unit }\end{array}$ & 0.0000 & 0.0000 & 0.0000 & 0.0000 \\
\hline ADF & $-49.6942^{* * *}$ & $-23.0308^{* * *}$ & $-45.4702^{* * *}$ & $-37.4422^{* * *}$ \\
\hline PP & $-50.3885^{\star \star \star}$ & $-56.1593^{\star \star *}$ & $-71.4637^{\star \star *}$ & $-38.5881^{* * *}$ \\
\hline
\end{tabular}

Notes: The Jarque-Bera (J-B) value corresponds to the test statistic for the null hypothesis of normality in the sample return distributions. ${ }^{* *}$ represents significance at $1 \%$.

Table 2 presents the estimates of Granger causality test among VIX vs. KSE, PKR and also Table 3 among VXFXI vs. KSE and PKR. All forecast reject the null hypothesis that VIX and VXFXI do not cause KSE and PKR while reversely is only possible in PKR foreign exchange markets. This suggests that volatility indices lead Pakistani financial markets, can act as fear gauge indicator and anticipate potential direction.

Table 2: Pairwise Granger Causality Tests

\begin{tabular}{llccc}
\hline Null Hypothesis: & & Obs. & F-Statistic & Prob. \\
\hline Stock Market & DLVIX does not Granger Cause DLKSE & 3320 & 14.4102 & 0.0000 \\
& DLKSE does not Granger Cause DLVIX & & 1.9045 & 0.1491 \\
\hline FX Market & DLVIX does not Granger Cause DLPKR & \multirow{3}{*}{3320} & 3.2866 & 0.0375 \\
& DLPKR does not Granger Cause DLVIX & & 2.5719 & 0.0765 \\
\hline
\end{tabular}

Table 3: Pairwise Granger Causality Tests

\begin{tabular}{llccc}
\hline Null Hypothesis: & Obs. & F-Statistic & Prob. \\
\hline Stock Market & DLKSE does not Granger Cause DLVXFXI & 1448 & 1.3338 & 0.2638 \\
& DLVXFXI does not Granger Cause DLKSE & & 5.7709 & 0.0032 \\
\hline FX Market & DLPKR does not Granger Cause DLVXFXI & 1448 & 3.0240 & 0.0489 \\
& DLVXFXI does not Granger Cause DLPKR & & 3.1765 & 0.0420 \\
\hline
\end{tabular}

\subsection{Methodology}

This study employs VAR model to assess the association between financial returns and implied volatility. Also, analysis the volatility shock to financial asset returns using impulse response functions. The article considers four variables; implied volatility index of S \& P 500 (VIX) returns in the USA financial market, China Exchange Traded Fund's Volatility Index (VXFXI) returns in the Chinese financial market, KSE-100 index returns and foreign exchange rate returns (PKR) in the Pakistani financial markets. The estimated VAR consists of lag 1 based on the Akaike criterion, and three pair variables are composed of the vector $Z_{t}$. The study estimates individual impact of VIX and VXFXI on equity and PKR exchange rate returns. Consider the following VAR (1) model;

$$
Z_{t}=C+B_{1} Z_{t-1}+\varepsilon_{t} \quad \varepsilon_{t} \sim \mathrm{N}(0, \mu)
$$

Where $Z_{t}$ consists of $3^{*} 1$ variables, $Z_{t-1}$ is one lagged dependent variables and $\varepsilon_{t}$ represents 
$3 * 1$ the residuals from VAR (1) model.

Once the VAR model is estimated, we then use impulse response function (IRF). The IRF indicate impulse response of a variable in the VAR process to the time path of its own shock and the shock to another variable in the VAR system. Plotting graphs of the IRF is a useful way of visually inspecting the dynamic association among the three variables in the VAR system.

\section{VAR Model Analysis}

In this section, we examine the impact of implied volatility returns of S \& P 500 index (VIX) and China Exchange Traded Fund's Volatility Index (VXFXI) on return series of KSE-100 index and PKR exchange rate using VAR (1) process and shock of VIX indices on these return-series. Table 4 and 5 summarizes the estimates of VAR (1) model in stock and foreign exchange markets respectively. In Table 4, past values VIX returns have a significant negative influence on the current values of the stock market which suggest that a rise in VIX volatility results in price falls of KSE-100 index. While the past values of VIX have a positive impact on PKR exchange rate which implies that an increase in VIX leads to depreciate the underlying exchange rate. This implies that VIX act as 'fear gauge' on both stock and exchange rate markets in Pakistan. Also, both Pakistani stock and exchange rate markets have a unidirectional relationship with VIX. Our results are consistent with the earlier literature (Kang, Yun-Jung, Ki-Hong, \& Sungkyun, 2014), (Kang, Ki-Hong, \& Yoon, 2014).

Table 4: Estimations of VAR (1) Model

\begin{tabular}{lccc}
\hline & DLVIX & DLKSE & DLPKR \\
\hline DLVIX(-1) & $-\mathbf{0 . 0 8 4 3}$ & $-\mathbf{0 . 0 1 5 5}$ & $\mathbf{0 . 0 0 1 3}$ \\
& $(0.0173)$ & $(0.0031)$ & $(0.0006)$ \\
& {$[-4.87244]$} & {$[-5.07858]$} & {$[2.04791]$} \\
DLKSE(-1) & 0.1735 & $\mathbf{0 . 1 4 4 4}$ & -0.0063 \\
& $(0.0971)$ & $(0.0171)$ & $(0.0035)$ \\
& {$[1.78638]$} & {$[8.43495]$} & {$[-1.78530]$} \\
DLPKR(-1) & -0.5547 & -0.0325 & $\mathbf{0 . 0 3 4 9}$ \\
& $(0.4763)$ & $(0.0840)$ & $(0.0173)$ \\
C & {$[-1.16456]$} & {$[-0.38756]$} & {$[2.01412]$} \\
& -0.0001 & $\mathbf{0 . 0 0 0 6}$ & $\mathbf{0 . 0 0 0 2}$ \\
& $(0.0012)$ & $(0.0002)$ & $(0.0000)$ \\
& {$[-0.05290]$} & {$[2.74036]$} & {$[4.11041]$} \\
\hline
\end{tabular}

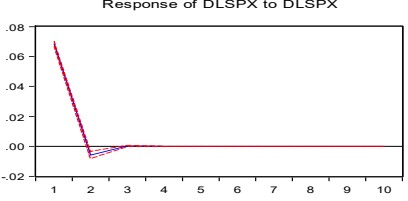

Response of DLKSE to DLSPX

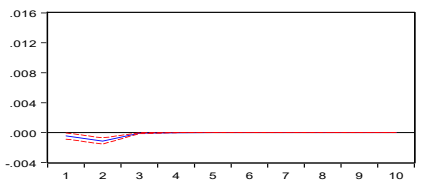

Response of DLPKR to DLSPX

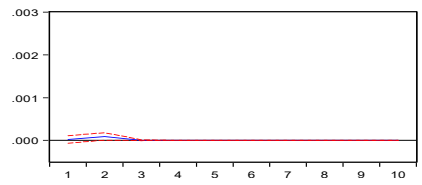

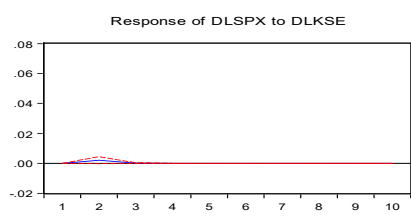

Response of DLKSE to DLKSE

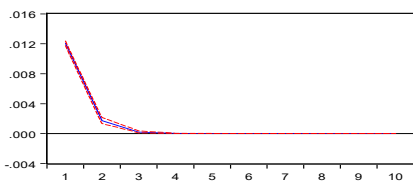

Response of DLPKR to DLKSE

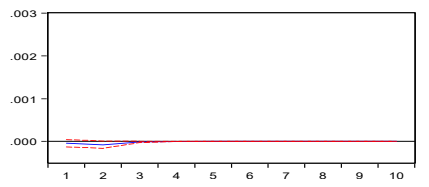

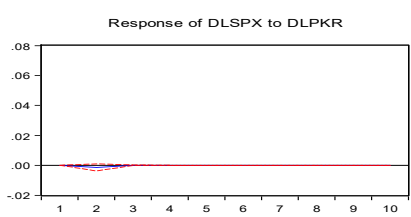

Response of DLKSE to DLPKR

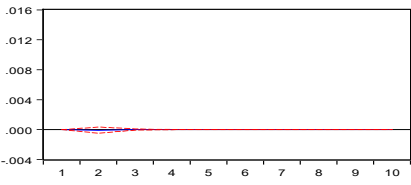

Response of DLPKR to DLPKR

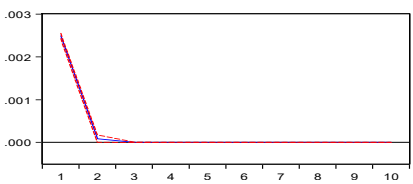


Figure 3: Impulse Response Function

Table 5 reports, the past values of VXFXI have a significant negative impact on the current values of the stock market which suggest that a rise in VXFXI volatility results in price fall in KSE-100 index. While past values of VXFXI have a positive impact on PKR exchange rate which implies that a rise in VXFXI leads to depreciate the underlying exchange rate like other Asian currencies. This implies that VIX act as 'fear gauge' on both stock and exchange rate markets in Pakistan. In addition, KSE-100 stock market and PKR exchange rate market has a unidirectional relationship with VXFXI. The literature states that equity and foreign exchange market returns should have negative correlation due to portfolio rebalancing. The inflow of local currency may cause depreciation in exchange rate while equity market is outperforming simultaneously (Hau \& Rey, 2006). However, estimates show that past values of KSE-100 index have a significant negative association with the exchange rate. Its reliable essence of uncovered equity parity (UEP) condition (MichaelMelvin \& JohnPrins, 2015).

Table 5: Estimations of VAR(1) Model

\begin{tabular}{lccc}
\hline & DLVXFXI & DLKSE & DLPKR \\
\hline DLVXFXI(-1) & 0.0191 & $\mathbf{- 0 . 0 1 3 8}$ & $\mathbf{0 . 0 0 2 2}$ \\
& $(0.0263)$ & $(0.0044)$ & $(0.0011)$ \\
& {$[0.72660]$} & {$[-3.11677]$} & {$[2.07979]$} \\
DLKSE(-1) & 0.1615 & $\mathbf{0 . 1 1 8 3}$ & $-\mathbf{0 . 0 2 5 6}$ \\
& $(0.1558)$ & $(0.0262)$ & $(0.0063)$ \\
DLPKR(-1) & {$[1.03612]$} & {$[4.52148]$} & {$[-4.08861]$} \\
& -1.2230 & 0.0224 & $\mathbf{0 . 1 2 2 6}$ \\
& $(0.6446)$ & $(0.1083)$ & $(0.0259)$ \\
C & {$[-1.89746]$} & {$[0.20735]$} & {$[4.72599]$} \\
& -0.0001 & $\mathbf{0 . 0 0 0 8}$ & $\mathbf{0 . 0 0 0 1}$ \\
& $(0.0013)$ & $(0.0002)$ & $(0.0001)$ \\
& {$[-0.10340]$} & {$[3.42819]$} & {$[2.75497]$} \\
\hline
\end{tabular}

Response to Cholesky One S.D. Innovations \pm 2 S.E.

Response of DLVXFXI to DLVXFXI

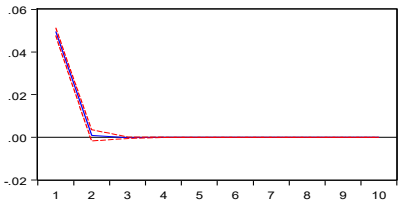

Response of DLKSE to DLVXFX

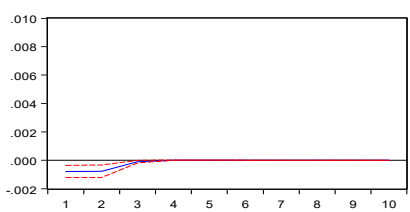

Response of DLPKR to DLVXFXI

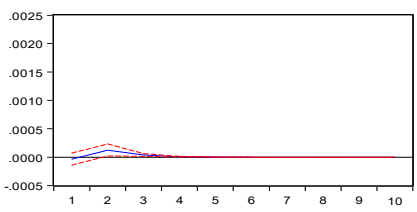

Response of DLVXFXI to DLKSE

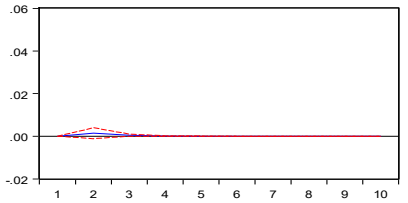

Response of DLKSE to DLKSE

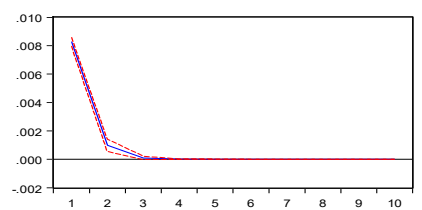

Response of DLPKR to DLKSE

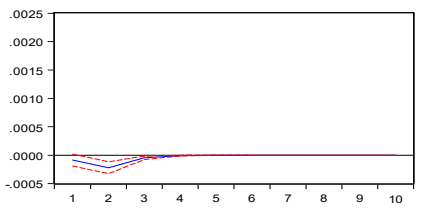

Response of DLVXFXI to DLPKR

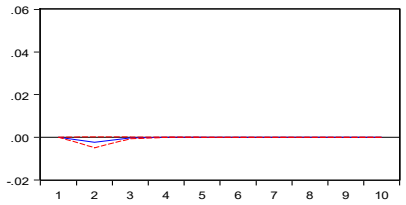

Response of DLKSE to DLPKR

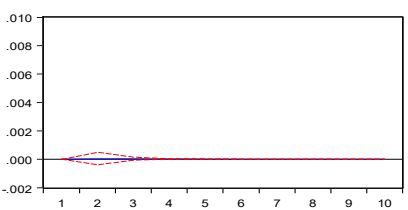

Response of DLPKR to DLPKR

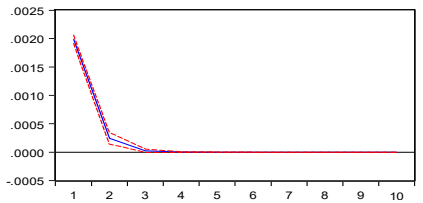

Figure 4: Impulse Response Function

Figures 3 and 4 demonstrate the shock of VIX and VXFXI on the financial return series of Pakistan 
equity and foreign exchange markets, respectively. As shown in Figure 3, the initial impact of VIX index on equity markets is negative while VIX has a positive influence on PKR foreign exchange rate. This evidence reveals that the VIX is considered as a signal of the fear gauge in both financial markets. In Figure 4, the impact of VXFXI index on the PKR returns is positive and significant, implying that a higher level of VXFXI index deteriorates the PKR depreciation. However, implied volatility index of VXFXI have a significant negative impact on KSE-100 stock market which indicates that an increase in VXFXI volatility turns equity prices to fall. These outcomes provide an imperative implication on the pattern of currency and stock sensitivities against global volatility. This reveals that adverse movements in global volatility in the USA and Chinese financial market have a significant impact and a rise in VIX causes an outflow of investment from financial markets of Pakistan. Moreover, our results may guide local and global investors to anticipate the potential direction of stock and exchange rate markets based on market volatility indices.

\section{Conclusion}

This study accommodates the spillover impact of volatility index of S \& P 500 (VIX) and China exchange-traded fund's volatility (VXFXI) on the emerging equity and foreign exchange markets of Pakistan. We examine the equity and forex return-volatility association for Pakistani financial markets to determine whether a return-volatility relationship is significant for these markets, as well as the strength and potential direction of this relation. In this context, we use a vector autoregressive (VAR) model and impulse response functions (IRF) for the differential periods.

The past values VIX returns have a significant negative influence on the current values of the stock market which suggest that a rise in VIX volatility results in price falls of KSE-100 index. The past values of VIX have a positive impact on PKR exchange rate which implies that an increase in VIX leads to depreciate the underlying exchange rate.

The past values of VXFXI have a significant negative impact on the current values of the stock market which suggest that a rise in VXFXI volatility results in price fall in KSE-100 index, while past values of VXFXI have a positive impact on PKR exchange rate which implies that a rise in VXFXI leads to depreciate the underlying exchange rate. This implies that VIX act as 'fear gauge' on both stock and exchange rate markets in Pakistan.

These outcomes provide an important implication on the pattern of currency and stock sensitivities against global volatility. This reveals that adverse movements in global volatility in the USA and Chinese financial market have a significant impact and a rise in VIX causes an outflow of investment from financial markets of Pakistan. Moreover, our results may guide local and global investors to anticipate the potential direction of stock and exchange rate markets based on market volatility indices.

\section{Acknowledgement}

This research is funded by China National Social Science Foundation, Project number: 15BGJ037

\section{References}

Cairns, J., Ho, C., \& McCauley, R. (2007). Exchange rates and global volatility: implications for Asia-Pacific currencies. BIS Quarterly Review, March.

Hau, H., \& Rey, H. (2006). Exchange rates, equity prices, and capital flows. Review of Financial Studies, 19, 273-317.

Kang, S. H., Ki-Hong, C., \& Yoon, S.-M. (2014). The impact of global volatility on Asian financial markets. Korea: National Research Foundation.

Kang, S. H., Yun-Jung, L., Ki-Hong, C., \& Sungkyun, P. (2014). The Impact of Global Volatility on Korean Financial Markets. International Conference on Trends in Economics (pp. Aug 13-14). Pattaya (Thailand): Humanities and Management (ICTEHM'14).

MichaelMelvin, \& JohnPrins. (2015). Equity hedging and exchange rates at the London 4 p.m. fix. Journal of Financial Markets, 22, 50-72.

Sarwar, G. (2012). Is VIX an Investor Fear Gauge in BRIC Equity Markets? Journal of Multinational Financial 
Management, Vol. 22, pp. 55-65.

Shu, C., He, D., Wang, H., \& Dong, J. (2016). The influence of Chinese and US financial markets on AsiaPacific. BIS Papers, No. 82, p. 171-181.

Whaley, R. E. (2000). The investor fear gauge. Journal of Portfolio Management, Vol. 26, pp. 12-17, 2000.

Whaley, R. E. (2009). Understanding VIX. Journal of Portfolio Management, Vol. 35, pp. 98-105, 2009.

Yang Cheng Lu, Y. C. (2012). Nonlinear Dynamics between the Investor Fear Gauge and Market Index in the Emerging Taiwan Equity Market. Emerging Markets Finance \& Trade, Vol. 48, pp. 171-191. 